\title{
Para un debate sobre los derechos colectivos de los pueblos en acción
}

\author{
Dino Di Nella ${ }^{1}$ | Universidad Nacional de La Plata, \\ Fernando Maitini ${ }^{2}$ Argentina \\ Patricia Giordana ${ }^{3}$ Universidad Nacional de Río Negro, \\ Argentina
}

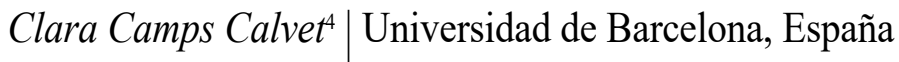
Pablo Casals ${ }^{5}$

Victoria Ibáñez $z^{6}$ Universidad Nacional de Quilmes, Argentina

Revista Derechos en Acción ISSN 2525-1678/ e-ISSN 2525-1686

Año 4/Nº 13, Primavera 2019 (21 septiembre a 20 diciembre), 711-728

DOI: https://doi.org/10.24215/25251678e352

Resumen: Este texto, pretende presentar y contribuir a la conformación de una sección especial dentro de la Revista ReDeA. Derechos en Acción, prevista a partir de su número 15, de otoño de 2020.

Se trata de una sección especial sobre Pluralismo Jurídico, Pueblos y Estados, para la Revista Derechos en Acción (ReDeA), propuesta a instancias del Programa Memorias, Pueblos y Estados, dependiente de la Secretaría de Relaciones Institucionales y radicado en el Centro de Investigación en derecho Crítico, de la Facultad de Ciencias Jurídicas y

\footnotetext{
1 Docente investigador de la Sede Atlántica de la Universidad Nacional de Río Negro. Responsable del Programa Memorias, Pueblos y Estados. Secretaría de Relaciones Institucionales. Facultad de Ciencias Jurídicas y Sociales, UNLP.

2 Secretario de Relaciones Institucionales de la Facultad de Ciencias Jurídicas y Sociales, UNLP.

3 Sede Atlántica de la Universidad Nacional de Río Negro.

4 Grupo Copolis. Bienestar, Comunidad y Control Social, Universidad de Barcelona.

5 Col lectiu de Solidaritat amb els Països Catalans.

6 Colectivo de Acción Jurídica, Social y Cultural Adalquí.
} 
Sociales de la Universidad nacional de La Plata, que empezó a gestarse en el año 2018, con la colaboración de diversos miembros del CIDerCrit, y el patrocinio y apoyo del Colectivo de Acción Jurídica, Social y Cultural Copolis-Adalquí (Sede Atlántica de la Universidad Nacional de Río Negro/Fundación Adalquí), el Col-lectiu de Solidaritat amb els Països Catalans, y el Grupo Interuniversitario Copolis. Bienestar, Comunidad y Control Social (Universidad de Barcelona).

Palabras clave: Pluralismo Jurídico; Pueblos; Naciones; Estados; Libre determinación.

Al inicio de un nuevo milenio, somos testigos de la dinámica reaparición de algunos movimientos interculturales, interseccionales y radicalmente democráticos en diversos pueblos naciones, que hoy carecen de su propio Estado, pero que en un pasado no tan lejano gozaron de un estatus independiente. Estos pueblos naciones están territorializados en divisiones políticas pertenecientes a diversos estados contemporáneos, y han dado origen a importantes y renovados movimientos socioeconómicos y culturales, que no tardaron en mutar hacia nuevas reivindicaciones político-identitarias. Pero, ¿Cuáles son los principales argumentos y prácticas a los que recurren los pueblos -minorías nacionales para esos estados- a fin de promover su derecho a una existencia plural y diferenciada? Y, ¿De qué modo los Estados responden a tales reivindicaciones?

Este texto, pretende presentar y contribuir a la conformación de una sección especial dentro de la Revista ReDeA. Derechos en Acción, prevista a partir de su número 15, de otoño de 2020.

Se trata de una sección especial sobre Pluralismo Jurídico, Pueblos y Estados, para la Revista Derechos en Acción (ReDeA), propuesta a instancias del Programa Memorias, Pueblos y Estados, dependiente de la Secretaría de Relaciones Institucionales y radicado en el Centro de Investigación en derecho Crítico, de la Facultad de Ciencias Jurídicas y Sociales de la Universidad nacional de La Plata, que empezó a gestarse en el año 2018 
con la coordinación de Dino Di Nella (actual responsable del Programa Memorias, Pueblos y Estados, Secretaría de Relaciones Institucionales, Facultad de Ciencias Jurídicas y Sociales, Universidad Nacional de La Plata), Clara Camps Calvet (Universitat de Barcelona), Patricia Giordana (Universidad Nacional de Río Negro), Victoria Ibañez (Colectivo Adalquí) y Pablo Casals (Col-lectiu de Solidaritat ambs els Països Catalans) y el Editor jefe de la Revista, Pablo Octavio Cabral, con la colaboración de diversos miembros del CIDerCrit, y el patrocinio y apoyo del Colectivo de Acción Jurídica, Social y Cultural Copolis-Adalquí (Sede Atlántica de la Universidad Nacional de Río Negro/Fundación Adalquí), el Col-lectiu de Solidaritat amb els Països Catalans, y el Grupo Interuniversitario Copolis. Bienestar, Comunidad y Control Social (Universidad de Barcelona).

En el contexto de los intereses y experiencias previas ya desarrolladas desde la Secretaría de Relaciones Institucionales, y entre los antecedentes y aportes previos del equipo editor que impulsa la sección, y que han dado origen a esta propuesta, se encuentran los resultados obtenidos en más de 20 proyectos y contratos de investigación sobre diferentes aspectos de la desigualdad sociocultural y jurídica en los últimos diez años, y en particular, de los resultados de las investigaciones I+D INFOJUS-2013 "Derechos Humanos y Desigualdades Sociales"; UNRN-40-C-649 "Dinámicas de género, familia y hábitat en mujeres urbanas mapuche"; proyecto europeo International Network for Comparative Analysis of Social Inequalities (INCASI; Programa Horizon 2020 (Marie Skłodowska-Curie Actions, Research and Innovation Staff Exchange, Grant Agreement, GA-691004); FEM2015-71218-REDT "Género, Ciudadanía y Políticas", y 2017-RICIP-00015 "Conflicto en Catalunya y represión política”. Asimismo, cabe nombrar también los proyectos de investigación "Pueblos, Estados y libre determinación. Entre el Lawfare mediático-judicial estatal y los procesos de resistencia intercultural e interseccional de los pueblos naciones mapuche y catalán" (ref. Solicitud PICT-2019-201900145) y "Pueblos, estados y libre determinación. Estudio 
sociojurídico de Puelmapu y el Principat de Catalunya" (ref. Solicitud PI-80520190300008RN) como propulsoras y garantes de la propuesta.

El conjunto de estas aportaciones, nos permite afirmar que los procesos de descolonizaciones, autodeterminaciones e independencias de los pueblos naciones marginalizados por los Estados coloniales y patriarcales del capitalismo mundial, están adquiriendo una nueva relevancia jurídica, política, social y cultural. Al estudiar los pueblos naciones sin Estado independiente identificamos una característica común que suele unirlas, y se refiere, por un lado, al grado de insatisfacción que sienten la mayoría de sus miembros por la situación en que se encuentra su pueblo. En efecto, a menudo el Estado es considerado como una institución política que les resulta extraña, de mera anexión y subordinación forzosa de sus pueblos naciones, o bien como una entidad que participa o es cómplice de la extracción, despojo o expolio de sus riquezas, mediante golpes de estado o el despliegue de una estrategia de lawfare mediático-judicial o guerra jurídica contra las personas líderes y referentes de sus pueblos naciones, o contra su posición ideológica, política y social, a través de la represión policial y la persecución políticojudicial de la desobediencia civil, la criminalización de sus protestas no violentas y la formulación de un derecho penal del enemigo contra ellos y ellas.

Por otro lado, se observa la autopercepción de pertenencia a un sujeto político colectivo e identitario, que se presenta en un devenir existencial diferenciado, proyectivo, performativo e ilusionante, constitutivos de procesos de resistencia intercultural e interseccional, que conllevan ejercicios autodeterminados de recuperaciones territoriales, posesiones e instituciones políticas ancestrales, en las que son parte destacada, mujeres en desobediencia civil no violenta a decisiones estatocéntricas.

La articulación de sentimientos y realidades similares provoca además la consolidación de movimientos soberanistas de base popular con distintos objetivos políticos, que abarcan desde la reivindicación de espacios de participación política 
colectiva de libre determinación -como referéndums o consultas vinculantes-, pasando por la delegación de poderes y la autonomía para la conformación de estados plurinacionales, hasta la emancipación política de los estados subordinantes y la subordinación política de los pueblos autodeterministas. Todos ellos, denuncian a su vez, una situación considerada injusta e insatisfactoria, por lo que hace a la extensión y calidad democrática, económica, social, política y de seguridad humana, resultante de la relación entre el Estado y los pueblos naciones así tratados como meras minorías nacionales. Pero, si bien las características de cada Estado -que difieren en cada caso- determinan el estatus de dichos pueblos y las respuestas y tipo de canalización institucional a sus demandas, la fuerza y carácter intercultural e interseccional que adquirieron en los últimos años los movimientos de emancipación política colectiva o nacional, están reconfigurando esas situaciones.

Efectivamente, las posturas políticas y reivindicaciones que le subyacen, ponen palmariamente de manifiesto, la tensión y los conflictos que existen entre el derecho de libre determinación de los pueblos naciones, y el principio de integridad, indivisibilidad o unidad territorial de los Estados. Identificar este dilema y comprender su proyección jurídica crítica en la vigencia o afectación sistémica de los derechos humanos de los estados y los territorios, es de una enorme importancia, impacto local y general, y relevancia académica y social. Las cuestiones que ameritan ser parte de una sección de una revista sobre los derechos en acción, implican en consecuencia, encuadrar su alcance a tres aspectos centrales, en torno a la necesidad de:

- Profundizar en la noción teórica y conceptual de la libre determinación de los pueblos naciones sin estados propios, en estados plurinacionales o bajo estados opresores de su derecho a la existencia diferenciada, a través de estudios y diversas contrastaciones teóricas y empíricas, desarrollando los actuales debates y teorizaciones sobre el pluralismno jurídico, la interculturalidad y la interseccionalidad respecto del capitalismo, el colonialismo y el patriarcado, 
desde una perspectiva jurídica crítica y comparada a nivel internacional;

- Indagar, visibilizar e interpretar hermenéuticamente las respuestas políticas y jurídicas estatales a los reclamos por la libre determinación de los pueblos, sus líderazgos sociales y sus intervenciones de acción directa en el espacio público, poniendo énfasis en el desplegamiento de los golpes de estado racializados, la estrategia del lawfare mediático-judicial o guerra jurídica contra las personas líderes y referentes de pueblos naciones, o contra su posición ideológica, política y social, a través de la represión policial y la persecución político-judicial de la desobediencia civil; la criminalización de sus protestas no violentas y la formulación de un derecho penal del enemigo; y

- Reflexionar sobre los procesos de resistencia intercultural e interseccional de los pueblos naciones, desde una perspectiva crítica de los derechos humanos, y poniendo énfasis en los procesos instituyentes y constituyentes, el abordaje sociojurídico de la recuperación y/o ocupación de territorios, posesiones e instituciones políticas ancestrales de los pueblos, en desobediencia civil no violenta a decisiones legislativas, ejecutivas o jurisdiccionales emitidas por órganos políticos y judiciales estatocéntricos.

La importancia e impacto a nivel local y general de esta propuesta, así como para la particular problemática que se propone abordar, viene dada por la trascendencia que están adquiriendo los procesos de defensa de los derechos colectivos llevados a cabo por los pueblos-naciones sin estado independiente, en estados plurinacionales o bajo estados opresores de sus derechos de libre determinación en su existencia colectiva o comunitaria diferenciada, y la interseccionalidad e interculturalidad de los procesos de resistencia popular.

De aquí surge la necesidad de abordar también, los antecedentes y noción actual de los "pueblos" y la "libre determinación" y sus tensiones con el monopolio de la producción 
y coactividad jurídica estatal. En efecto, el análisis y estudio de los pueblos y naciones sin estado propio y su derecho a la libre determinación ha ido evolucionando sostenida pero lentamente, desde finales del siglo XIX, si bien a mediados del Siglo XX empezó a tener una mayor significación, sobre todo en los análisis del derecho internacional público, el derecho político, el derecho constitucional, el derecho administrativo, el derecho de los pueblos originarios, el derecho indígena y la sociología jurídica. No obstante, es a partir de la primera década del siglo XXI, que este abordaje se ha expandido acelerada e intensamente en casi todos los países del entorno. Así, a nivel comparado e internacional, cabría destacar un crecimiento de estas investigaciones, que podemos agrupar en cinco ejes centrales a) las reflexiones más teóricas sobre sus significados, percepciones, racionalidades, dilemas analíticos, construcciones jurídicas, discursos o identidades; b) las políticas públicas y legislativas enmarcadas en los regímenes de organización territorial de los estados; c) los enfoques desde la génesis de los movimientos de liberación nacional como eje central del análisis; d) los estudios de pobreza y exclusión social estructurales y e) las autobiografías o historias de vida de luchadores y luchadoras sociales por la liberación de sus pueblos (ver selección bibliográfíca de los principales autores y autoras de actualidad, efectuada por el equipo del proyecto, en https://www.adalqui.org.ar/bibliografia/)

Desde esta producción académica, puede afirmarse que las principales aproximaciones a la noción de "pueblo", en tanto que un concepto jurídico y político indeterminado, y la necesidad de diferenciarlo de otras nociones similares, lo han vinculado a su configuración y alcance como sujeto colectivo de derechos, en tanto que pueblos "coloniales", "sometidos a dominación extranjera", "movimientos de liberación nacional", "conjunto de habitantes de un Estado", "grupo diferenciado dentro de un Estado", "grupo étnico-cultural", "minoría nacional", y pueblo "indígena", entre otras. Todas ellas, derivadas en gran medida, de la Carta, normas y resoluciones de las Naciones Unidas y 
sus órganos, tales como la resolución 1541 (XV) y resolución 1541 (XV), de 1960; la resolución 2625 (XXV), de 1970, el Pacto Internacional de Derechos Civiles y Políticos, de 1966, los Convenios 107 (1957) y 169 (1989) de la OIT, y las declaraciones de derechos humanos, como la de los pueblos indígenas y tribales (2007). Tanto los/las cientistas sociales, como los movimientos sociales vinculados a los grupos étnico-culturales y los Estados y entidades multilaterales, han tratado de hacer valer sus respectivas concepciones de "los pueblos". Del mismo, modo, la libre determinación (o autodeterminación), es el derecho de un pueblo a decidir sus propias formas de gobierno, perseguir su desarrollo económico, social y cultural, y estructurarse libremente, sin injerencias externas, en tanto que derecho humano colectivo de ejecución continuada. Es, a su vez, un principio fundamental del derecho internacional público de carácter inalienable, que genera obligaciones erga omnes para los Estados, y que devino, de acuerdo con muchos autores, en norma de ius cogens. Las posturas políticas y reivindicaciones que le subyacen, ponen de manifiesto la tensión y los conflictos que existen entre el derecho de libre determinación y el principio de integridad, indivisibilidad o unidad territorial de los Estados.

Durante el siglo XIX, se lo consideró principalmente para evidenciar la ilegitimidad de las intervenciones de los estados coloniales imperialistas europeos sobre las poblaciones $\mathrm{O}$ "naciones" que se pretendían independientes, como en Abya Yala - Amerindia (tanto en los Estados Unidos del norte -1776-, como en las guerras independentistas del sur del continente, contra las fuerzas realistas españolas y portuguesas -18091824-). En los principios del siglo $\mathrm{XX}$, tras la primera guerra mundial y la organización de la Sociedad de Naciones, la libre determinación adquirió relevancia como un principio político, respaldado desde diversas posturas ideológicas como el liberalismo y el socialismo. Pese a ello, el poder que aún preservaban los estados imperialistas coloniales europeos impidió que tuviera efectos jurídicos en el Derecho internacional. Esto cambió desde la segunda mitad del siglo XX, con la creación de 
la organización de las Naciones Unidas y su Carta de 1945, que incluyó los principios de "igualdad de derechos" y "libre determinación de los pueblos", como base para la paz y el orden internacional. En este momento, la mayoría de los pueblos del mundo estaban sujetos a colonialismo y se les negaba de hecho la autodeterminación, por lo que la Carta previó diversos sistemas relativos a los territorios no autónomos o de administración fiduciaria. No obstante, no se consideró la eliminación inmediata del régimen colonial ni se redujo el carácter equívoco de la autodeterminación y la noción de pueblo. De tal forma, que los Estados imperialistas retuvieron bajo su control directo a los pueblos naciones de sus colonias, así como los nuevos estados del continente de Abya Yala-Amerindia, construídos sobre la base de genocidios y despojos territoriales, la división política colonial y la hegemonía y control estatal de las clases dominantes criollas de origen europeo, retuvieron bajo su control y subordinación directa a los pueblos naciones indígenas. Entonces, la subjugación de los pueblos naciones europeos de territorios vecinos o colindantes a los de las metrópolis de los reinos coloniales, quedaron invisibilizados y sofocados casi por completo. En cambio, no tardaron en surgir movimientos y guerras de liberación nacional de los pueblos de Asia, África y Abya Yala.

En ese contexto, las normas y resoluciones de las Naciones Unidas citadas también influyeron en el desarrollo del derecho de la libre determinación de los pueblos, aunque evidencian un camino sinuoso. Así, en 1957 el Convenio 107 de la OIT de la ONU (que asumía para América latina la cuestión de los pueblos indígenas, negando no solo un derecho a la autodeterminación de los mismos, sino incluso su carácter de pueblos); en 1960 las resoluciones 1514 (XV) y 1541 (XV) (que concretaron como pueblos titulares del derecho de libre determinación, solo a los grupos étnicos culturales de colonias separadas geográficamente (por ultramar) del estado de la metrópoli); y en 1966 los Pactos Internacionales de Derechos Humanos (que incluyó la libre determinación de los pueblos como derecho universal). En 
1970 se adoptó la resolución 2625 (XXV), estableciendo que la libre determinación es un derecho de todos los pueblos y que conlleva obligaciones para todos los Estados. Sin embargo, en 1989 la OIT adoptó el Convenio 169, en el que si bien se reconoce el carácter de pueblos -y ya no poblaciones- a los grupos étnicos-culturales indígenas y se les admite cierto derecho a su autogobierno, a sus recursos naturales, y a vivir de acuerdo a su cultura y cosmovisión, se vuelve a establecer la imposibilidad de invocarlo como base para afectar la integridad territorial de los estados ya constituidos.

Las exigencias del conjunto de estas normas y resoluciones generaron, así, cuatro estatus jurídicos y políticos internacionales de los pueblos (centrados en, o marginalizados de, su acceso al estado propio):

I) los grupos étnicos-culturales que habitaban sus territorios ancestrales y controlaban los estados imperialistas centrales, a los que se los asumió como pueblos-naciones en estados independientes, en ejercicio actual de su derecho a la autodeterminación. Se trata de los pueblos que hegemonizaron el control estatal, asimilando y/o subordinando -según el caso- a los demás grupos étnicos-culturales que habitaban su territorio ancestral (como los ingleses, o los castellanos, entre otros).

II) los grupos étnicos-culturales que habitaban territorios coloniales ultramarinos de los estados imperialistas centrales, a los que se les reconoció como pueblos, y también su derecho a la autodeterminación.

III) los grupos étnicos-culturales que habitaban territorios coloniales ultramarinos de los estados constituidos o sobrevenidos después de los procesos de liberación de los imperialismos centrales (como los estados de Abia Yala-Amerindia después de las independencias del imperio español, frances o británico en el siglo XIX, y los estados frutos de la descolonización imperialista de Africa, en el siglo XX), a los que se les reconoció como pueblos (más 
específicamente, como pueblos indígenas), aunque no se les reconoció su derecho a la autodeterminación.

IV) los grupos étnicos-culturales que habitaban territorios coloniales vecinos o colindantes de la metrópolis de los estados imperialistas centrales (como los europeos de Escocia, Irlanda, Trentino, Eskal Herria o Països Catalans), a los que no se les reconoció como pueblos, ni tampoco su derecho a la autodeterminación.

Como puede observarse, los dos primeros grupos gozaron del reconocimiento de sus derechos a y/o ejercicio de la autodeterminación, a unos, por su efectivo ejercicio desde el control de los estados ya constituidos, y a otros por encontrar ampliamente reglamentados las formas de acceso y ejercicio de la autodeterminación (las colonias ultramarinas). En cambio, a los dos últimos grupos, que son las situaciones de colonialismo interno o intracontinental (no ultramarino), de pueblos-naciones en estados ya constituidos, se los excluía. Y aún así, cabe distinguir que para los del tercer grupo (pueblos indígenas) se les acabó reconociendo el estatuto de pueblos y su derecho a la autodeterminación interna dentro de un estado (aunque sin prever su instrumentación jurídica internacional), mientras que a los del cuarto grupo (pueblos de territorios continentales colindantes de los pueblos hegemónicos de los estados europeos coloniales) su estatuto es el de una unidad regional o minoría nacional más. No obstante, es incontestable que las posturas políticas y reivindicaciones que le subyacen, ponen de palmariamente de manifiesto la tensión y los conflictos que existen entre el derecho de libre determinación de los pueblos naciones, y el principio de integridad, indivisibilidad o unidad territorial de los Estados.

Abordar estos dilemas, como quiere hacerse desde la sección propuesta, es de gran importancia, impacto local y general, y relevancia académica y social, por diversas razones, que sintetizaremos aquí, en tres principales.

En primer lugar, porque es la realidad de los 5000 pueblos naciones marginalizados y subordinalizados a los poco 
más de 200 estados del capitalismo global que los gobiernan y excluyen del sistema de decisiones que se adoptan sobre los temas que les afectan. Así, emergen indispensables hoy, los estudios comparados de los pueblos-naciones originarios pero marginalizados del sistema de poder-mundo, tanto de África, Oceanía y Abya Yala-Amerindia (como los pueblos indígenas u originarios), como de Europa y Asia (Hong Kong, Kurdistán, Palestina, Catalunya, Irlandia del Norte, Escocia, Euskal Herria, entre otros).

En segundo lugar, porque se observa como respuesta estatal el desplegamiento de una común y homogénea estrategia de lawfare mediático-judicial contra las personas líderes y referentes de pueblos naciones sin estado, en estados plurinacionales o sometidos en estados opresores del derecho a su existencia diferenciada. Todo, contextualizado en complejas y opacas tramas relacionales entre sectores del poder judicial, las instancias policiales y los medios de comunicación concentrados en la intencionalidad editorial de los grupos económico financieros que manejan los distintos soportes de información y comunicación. Tal estrategia debe ser comprendida como construcción de un espectáculo que requiere de la sinergia entre el juicio mediático criminalizante y el proceso judicial estatal. Su trascendental relevancia radica además en que, cuando esta estrategia del lawfare se utiliza para deslegitimar y proscribir la disidencia política, social y cultural de los pueblos naciones contra los regímenes neoliberales, coloniales y patriarcales de los estados del capitalismo global, se produce una afectación sistémica de derechos humanos, con una alta regresividad en la vigencia y ejercicio de los derechos políticos, económicos y culturales de esos pueblos naciones del mundo.

En tercer lugar, porque los pueblos naciones subyugados, protagonizan histórica y actualmente vigorosas luchas políticas de particular trascendencia por su radicalidad democrática participativa, ejercida como procesos de ruptura pacífica y confrontativa con las agencias de la institucionalidad jurídica estatal. Ello se observa, especialmente, ante los actos de desobediencia 
civil no violenta más trascendentes y masivos de la historia de Europa, Asia, Africa y Abya Yala que se estan produciendo en los últimos años, a los fines decidir sus futuros políticos en consonancia con sus culturas y cosmovisiones, y en contra de lo dispuesto por múltiples órganos de carácter político y judicial de los estados. A su vez, tales luchas políticas se inbrincan en destacados procesos interseccionales y situados de actuación sociocomunitaria (anticapitalistas-ecologistas, anticolonialistascomunitaristas interculturales, antipatriarcales-feministas decoloniales), que ponen de relieve el impacto de los procesos de mundialización de la desigualdad estructural que combaten, en los propios grupos de crianza y desarrollo desde dónde brotan las rebeldes relaciones sociales y de cuidados en la vida cotidiana. Esto reviste de particular trascendencia en la actualidad, por la radicalidad democrática y participativa de las mujeres que las protagonizan, como colectivos históricamente vulnerabilizados, estigmatizados, y marginalizados de los procesos sociales y políticos subyacentes.

Siendo así, el impacto principal de la sección pasa por la aprehensión conceptual y procesual que posibilitan y/o impiden el ejercicio pacífico - no violento de la libre determinación de estos pueblos, como vías internas y/o externas de relación entre pueblos iguales en derechos. En este sentido, cabe mencionar que los pueblos naciones marginalizados suelen tener reconocido el derecho a una autodeterminación interna en toda o parte de su extensión, limitando a casos muy estrictos el ejercicio de su autodeterminación externa. Son los estados y pueblos naciones que están frente a esta realidad, y su comprensión, las que se constituyen uno de los objetivos centrales del análisis. En cada uno de los continentes, son numerosos. Varios de estos pueblos, se han nucleado en la Organización de Naciones y Pueblos No Representados (Unrepresented Nations and Peoples Organization, UNPO, por su sigla en inglés), que es una organización internacional cuyos miembros son poblaciones indígenas, minorías y habitantes de territorios no soberanos u ocupados (https://unpo.org; rec. 12-08-2019). La 
autodeterminación de los pueblos-naciones, la democracia, la no violencia, el ambientalismo y los derechos humanos, son los cinco principios centrales de la organización. Y en ese marco, es que en los últimos años, se observa la apelación a la desobediencia civil no violenta y los procesos de acción directa para definir democrática y participativamente su futuro político, social y económico. Estos pueblos han reivindicado su derecho a la libre determinación para alcanzar una mayor autonomía y la devolución del control de sus territorios ancestrales e instituciones políticas tradicionales. Los despojos y expolios que como pueblos-naciones han padecido, se han hecho en la gran mayoría de los casos, en fragante violación de pactos preexistentes (vinculantes por su letra, por ius cogens, por pacta sunt servanda, y por el conjunto del derecho internacional público aplicable), no solo sin procesos de consulta previa y consentimiento libre e informado, sin la reparación por los daños causados -en términos de restitución del ejercicio de derechos- ni un mínimo resarcimiento, y sin su participación en los pretendidos beneficios, sino que instrumentados mediante verdaderos genocidios y etnocidios, que se pretenden legitimar, sin más, por el supuesto derecho de conquista (el uti possidetis juris románico).

En efecto, y en la actual fase histórica, la definición identitaria de estos sujetos políticos colectivos, se forjaron sobre la base de nacionalismos étnicos-culturales que luchaban por sus pueblos y sus libertades nacionales. Su sentido de pertenencia se visualizaba claramente en las objetivables especificidades lingüísticas, sociales, culturales, económicas e históricas que estas etnias presentaban. Ahora bien, a consecuencia de los genocidios, despojos y expolios, aculturación y grandes migraciones durante varios decenios, la composición étnica de cada uno de estos pueblos se ha visto radicalmente alteradas. Más específicamente, los principales de estos cambios son: a) la liquidación de las instituciones políticas propias y las dificultades para restituir su ejercicio, a partir del despliegue de políticas culturales, educativas y de memoria pública de aculturación y 
asimilacionismo; b) la expansión de las inversiones extractivistas de grandes corporaciones vinculadas principalmente a los mercados mundiales a través de la subjunción a las metrópolis, resultando, entre otros, en el despojo y/o expolio de sus territorios, recursos naturales y humanos, productivos, comerciales e industriales; c) la modificación de la estructura demográfica, provocados por verdaderos flujos migratorios intra e interterritorial de desplazamiento rural y emplazamiento en sectores periurbanos; y d) la uniformación del sistema de vida y de la cultura, general en el mundo capitalista tras la guerra de 19391945, hacia el exitismo meritocrático, el consumismo y el individualismo, y su impacto en la conformación de frustaciones estructurales que conllevan diversas formas de actualización histórica del fascismo social, así como el desarrollo de nuevas estrategias de contrucción sociocomunitaria de proyectos colectivos de futuro.

Esta nueva situación, estaría haciendo tambalear las bases o elementos objetivos anteriormente aducidos de homogeneidad étnica, en que siempre se habían fundamentado el nacionalismo histórico de los pueblos. La incertidumbre resultante, teórica, ideológica y fáctica, se estaría traduciendo en cinco cuestiones principales que, sin perjuicio de otras, merecen ser indagadas profusamente.

En primer lugar, la posible apertura de conformaciones de identidades nacionales mas basadas en los elementos subjetivos, volitivos o autopercibidos. Es decir, políticas de pertenencia basadas en la voluntad de reconocerse como parte de un sujeto político colectivo con un proyecto emancipatorio y de futuro en común, sea en estados independientes o en nuevos estados plurinacionales, así como también, y paralelamente, la actualización histórica de los sujetos políticos colectivos representados en los estados capitalistas, coloniales y patriarcales, subordinacionistas del emergente entramado de disidencias políticas, sociales y culturales.

En segundo lugar, si el sistema patriarcal, colonial-extractivista y puramente rentístico -que siguió caracterizando las 
extructurales relaciones comerciales y laborales de explotaciónno indujo también a la articulación de estrategias de resistencia sociocomunitarias interseccionales y situadas, que podrían estar haciendo converger en las mujeres que lo protagonizan, a los distintos movimientos de derechos humanos, feministas y ambientalistas, con los identitarios de los pueblos naciones.

En tercer lugar, si la previsible necesidad de interacción y posibilidad de integración de toda la población residente en un determinado espacio físico, es decir, si la conciencia de identidad étnica colectiva, entró o no en crisis, pues, para poder englobar a todos y todas las recién radicadas en el territorio, para poder aferrarse a la cada vez más inexistente homogeneidad, parecería preciso renunciar a encuadrar dentro del gentilicio nacional, a los esparcidos por las ciudades del propio espacio geográfico y del mundo que, por causas diversas, ni viven ni trabajan ni sostienen las pautas socioculturales ni las respectivas caracterizaciones étnicas, en el propio territorio. Mas específicamante, parecería ser que las conformaciones identitarias colectivas fundadas en dicho basamento, podrían implicar el reconocimiento de la diversidad e interculturalidad intrínseca de las sociedades actuales, la igualdad material de derechos individuales y colectivos, y la necesidad de una radicalidad democrática, que pretendería poner en el centro la participación política directa en el gobierno y la toma de decisiones, sobre los asuntos que les afectan.

En cuarto lugar, si el alcance y profundidad de las respuestas estatales a los reclamos por la libre determinación, es decir, la forma en que estos pueblos, sus liderazgos sociales y sus intervenciones de acción directa en el espacio público, habrían sido estigmatizadas, rotuladas, criminalizadas y/o reprimidas, observándose los procesos por medio de los cuales pudo eventualmente llegarse -lawfare mediante- a la sistemática persecución mediática-judicial, a la privación de libertad de sus dirigentes, y a la provocación de daños y lesiones gravísimas (incluso el asesinato) de sus militantes sociales.

Y en quinto y último lugar, cabría indagar en la forma de ejercicio del derecho a la protesta social y política de los pueblos 
naciones, y eventualmente, en una pretendida autosatisfacción de su derecho a la libre determinación mediante el ejercicio de la recuperación y/o ocupación de sus territorios, posesiones e instituciones ancestrales, en desobediencia civil no violenta a decisiones legislativas, ejecutivas o jurisdiccionales emitidas por órganos políticos y judiciales estatocéntricos.

De esta breves reflexiones no se extraen sino estas preguntas, que acaban perfilando los objetivos de la sección propuesta. ¿Cómo se configuran y que representan para sus actores y actrices, sus identidades y pertenencias a sujetos políticos colectivos nacionales?, ¿Cuáles son las características del lawfare mediático-judicial como respuestas a los reclamos por la libre determinación, y cuales sus efectos sobre el ejercicio de derechos humanos políticos, económicos, sociales y culturales?, ¿Cómo lo gestionan los mass-media, según sus respectivas intenciones editoriales?, A la luz de realidades tan diversas, ¿puede comprobarse el desarrollo de elementos objetivos de identidad compartida como la cultura, la lengua y la organización jurídica, política, social y económica de un pueblo nación, sin un estado propio?; ¿Puede resolverse sociodemográficamente el dilema de integrar una parte de una población, que, pese a coresidir en un mismo territorio que resulta de ocupación ancestral de un pueblo-nación, no ha asumido todavía la realidad nacional como sus ocupantes ancestrales y actuales?. ¿El derecho de libre determinación de los pueblos naciones sin estados propios, en estados plurinacionales o bajo estados opresores de su derecho a la existencia diferenciada, han efectivamente cambiado en sus características jurídicas y sociales esenciales, hacia condiciones predominantemente subjetivas-volitivas de pertenencia a esos sujetos políticos colectivos, y nuevas interpretaciones judiciales que lo amplían como derecho de todos los pueblos naciones del mundo?. ¿Qué lugar tiene el derecho en todo esto?.

Es en torno a estas preguntas y dilemas, que se dirigirá el conocimiento derivado de la sección, y sobre la que define su misión, objetivos, ámbito territorial, formatos, lenguas, periodicidad, vigencia, indicadores de calidad, asociatividad, 
organización interna y política editorial específica, dentro de los lineamientos generales ya establecidos de la Revista Derechos en Acción. Todos aspectos que serán anunciados ya, desde su próximo número. Entre el abordaje de los golpes de estado y el Lawfare mediático-judicial, y los procesos de resistencia intercultural e interseccional de los pueblos naciones, se impulsará este debate, sobre los derechos colectivos de los pueblos en acción, que no puede ser sino su pleno ejercicio de la libre determinación. 